\title{
Institutional Strategies for Capturing Socio-Economic Impact of Academic Research
}

\author{
Rosa Scoble, Keith Dickson, Steve Hanney and G J Rodgers \\ Brunel University, Uxbridge, Middlesex UB8 3PH, UK
}

Corresponding author: Rosa Scoble, rosa.scoble@brunel.ac.uk, +44 (0)1895266031

\begin{abstract}
$\underline{\text { Abstract }}$
Evaluation of socio-economic impact is an emerging theme for publicly-funded academic research. Within this context, the paper suggests that the concept of institutional research capital be expanded to include the capture and evaluation of socio-economic impact. Furthermore, it argues that understanding the typology of impacts and the tracking from research to impact will assist the formulation of institutional strategies for capturing socioeconomic impact.

A three-stage approach is proposed for capturing and planning activities to enhance the generation of high-quality impact. Stage one outlines the critical role of user engagement that facilitates the tracking of such impact. Stage two employs an analytical framework based on the criteria of 'depth' and 'spread' to evaluate impacts that have been identified. Stage three utilizes the outcomes of the framework to devise strategies, consisting of either further research (to increase depth) or more engagement (to increase spread) that will improve the generation of higher quality impact.
\end{abstract}

\section{Background}

Over the last 20 years, the UK higher education sector has become increasingly competitive. The entry of new institutions into the university sector in 1992, the growing internationalisation of higher education and the decrease in central government funding (in terms of unit of resource) has forced institutions to devise and establish strategies for maximising their sources of income. This period has also seen the increasing influence of league tables, both national and international, and the association of reputation with ranking.

Within this environment, research has progressively been seen as an activity that, if well managed, can enhance an institution's reputation and international standing and also generate potentially high economic returns. It is within this context that research activity can be described as an institution's research capital. (As the next paragraph makes clear, the use of the term 'research capital' is more specific to academic activities than the manufacturing/service activities normally embraced by the traditional, economic-based use of the term. See Griliches, 1986, or Mansfield, 1980, for the latter definition.)

The core of what constitutes the institution's research capital is well defined and understood by the academic community, higher education senior management and funding agencies. Research activities such as the production of publications/outputs, the ability to attract external funding for research (whether from public or private organisations) and the training of future researchers through post-graduate research programmes are all at the core of an institution's research capital. Moreover, the boundaries and definitions of research capital 
have been further consolidated over the last 20 years, through a number of national research assessment exercises and the programmes of research funding agencies.

However, a change in the political landscape has seen a new emphasis placed on the measurement of the socio-economic impact of publicly funded research. This emerging theme was a corner-stone of the government's 10-year (2004-2014) plan for science and innovation (HM Treasury, Department for Education and Skills, Department of Trade and Industry, 2004). In October 2006 a joint Office of Science and Innovation (responsible for co-ordination of the Government's science and technology policies) and Treasury Steering group was formed and subsequently the recommendations from this group developed into the former Department of Innovation, Universities \& Skills - DIUS (now the Department for Business, Innovation \& Skills - BIS) investment framework (DIUS, 2008). This sets out a reporting structure, the Economic Impact Reporting Framework (EIRF), for the Research Councils UK (RCUK). The growing importance of socio-economic impact can also be seen in the new proposals from the Higher Education Funding Council for England (HEFCE), which also reports to BIS, to introduce the assessment of socio-economic impact as part of their Research Excellence Framework, the replacement for the well established Research Assessment Exercise, that was last deployed in 2008 (HEFCE, 2009).

The challenges of capturing and assessing socio-economic impact are not new either in the UK or internationally. A recent report by RAND Europe (Grant, Brutsher, Kirk, Butler, \& Wooding, 2010) identifies 14 different frameworks to assess impact from Australia, the United States, the Netherlands, Sweden, Canada, Japan and the UK (the most notable of which are: the Australian Research Quality and Accessibility Framework, the US Program Assessment Rating Tool and the Dutch Evaluating Research in Context).

The challenge for institutions with a broad disciplinary base, given the breadth of definitions of socio-economic impact, is how to define, identify and capture impact systematically for different disciplines and different types of research. Even more important is the challenge to devise strategies for actively supporting and facilitating the pathway from research to impact. The current body of knowledge on the impact of academic research gives an insight into how management strategies can be developed to integrate socio-economic impact into the institutional research capital.

\section{Current understanding of the impact of research}

Many funding agencies and charities have embarked in impact studies including: The British Academy in January 2004, the Medical Research Council in collaboration with the Wellcome Trust and the Academy of Medical Sciences in 2008 (Health Economics Research Group, Office of Health Economics, RAND Europe, 2008), and the Arthritis Research Campaign in 2009 (Wooding, Nason, Starkey, Hanney, \& Grant, 2009). Most notably, the Economic \& Social Research Council (ESRC), one of the seven councils that make up the Research Councils UK, commissioned in 2006 a series of impact case studies aimed at identifying the impact of the research it had funded (ESRC, 2009).

Impact studies use a number of methods and tools to identify and evaluate impact. Several of these methods, such as the Payback Framework developed at Brunel University (Buxton \& Hanney, 1996; (Buxton, Hanney, \& Jones, 2004), define impact on the non-academic community as one of the many dimensions of research impact. In these evaluative frameworks, knowledge generation (academic impact), capacity building (training and career development), and socio-economic impact (impact on policy, practice and the wider community) are all different expressions of the value of research. This view acknowledges that research might generate different types of impacts, at different times and with different 
intensities, and asserts that by capturing all these dimensions of impact we will have a true representation of the value of the research.

Conceptually this view has been reinforced by the DIUS Economic Impact Reporting Framework which is structured around a number of categories (dimensions) that define economic impact (DIUS, 2008). These categories are:

\begin{tabular}{ll}
\hline Overall economic impact: & $\begin{array}{l}\text { Increased productivity } \\
\text { Improved welfare }\end{array}$ \\
\hline Innovation outcomes and outputs: & $\begin{array}{l}\text { Technological innovation } \\
\text { Wider innovation }\end{array}$ \\
\hline Knowledge generation: & $\begin{array}{l}\text { Human capital } \\
\text { Stock of publicly available knowledge }\end{array}$ \\
\hline Investment in the research base and & Expenditure on R\&D \\
innovation: & Expenditure on innovation. \\
\hline
\end{tabular}

Table 1 - Economic Impact Reporting Framework Categories

It is interesting to note that the Economic Impact Reporting Framework includes all aspects of academic research as activities that result in economic impact, including what we might define as the research capital mainly aimed at the academic community. This interpretation of economic impact re-affirms the concept that socio-economic impact is not a distinct outcome, sometimes perceived as in conflict with the 'pure' creation of knowledge, but can be seen as just another dimension of academic research.

From an institutional perspective, therefore, socio-economic impact should be seen as an addition to the research capital that can be captured and harnessed as one of the many outcomes of academic research activity.

\section{Institutional challenges}

While the majority of the impact studies conducted by funding agencies might vary in approach and methodology, they can have the advantage of focusing on a well defined set of research activities with clear inputs, objectives and research plans. However, they often run into problems of attribution that can sometimes be addressed by examining a wider range of an individual's portfolio of research. The challenge for higher education institutions is to identify and catalogue impacts that are generated from a high volume of individual research activities from a number of very disparate disciplines.

There are currently several well established tools and methodologies to capture academic impact, including citations and bibliometric information (Jarwal, Brion, \& King, 2009). However, socio-economic impact has not yet been established as a mainstream outcome of research activity that can be captured and harnessed by institutions. Therefore, there are very fewer tools available and less understanding on how to identify, capture and evaluate systematically socio-economic impact on a wide scale.

There could be a number of strategies for the identification of impact at an institutional level: socio-economic impact could be identified by the individual researcher, through local arrangements within research centres and groups, or through central research support facilities. Nevertheless, whilst researchers in some disciplines might be accustomed to seeing socio-economic impact through working closely with their users' communities, this would 
not be true for all researchers, research groups or disciplines. Therefore, the first step for the identification of socio-economic impact must be a programme of education to share and embed in the academic community definitions of socio-economic impact and how to recognise it.

Central research support teams within institutions have a key role to play in supporting research (Shelley, 2010) and, therefore, to expand their responsibilities to include the identification and capturing of socio-economic impact. They can both support individual researchers and groups in identifying socio-economic impact, as well as systematically 'scan' research activities and outputs, so as to be alerted to those activities that have a potential for creating socio-economic impact. Since, it is accepted that only a proportion of research activity will create significant socio-economic impact, institutions have to adopt strategies to focus on those that have characteristics that might lead to the adoption of their findings by policy makers, users' communities, or might influence social welfare and quality of life.

\section{Defining socio-economic impact}

One of the first important points when defining socio-economic impact is the distinction between 'dissemination' and 'impact'. The report on the ESRC International Symposium Approaches to Assessing the Non-Academic Impact of Social Science Research (ESRC, 2005, p. 23) has noted, as one of its main conclusions, that while disseminating to a wide range of audiences is positive, impact has to be evidenced by the application of the research outcomes by the user or community. It also highlights that, "it cannot be assumed that the former [dissemination] naturally or inevitably leads to the latter [impact]". Godin and Doré (2004) reaffirm the distinction between outputs and impacts where the latter are defined as changes in society directly related to the research activity. This was also a key element in Buxton and Hanney's distinction between Primary Outputs, Secondary Outputs, and Impacts or Final Outcomes (Buxton and Hanney, 1996).

The Warry Report, commissioned by the UK Director General of Science and Innovation, asserts that, "an action or activity has an economic impact when it affects the welfare of consumers, the profits of firms and/or the revenue of government" (RCUK, 2006, p. 10). Yet, it goes further by adding to economic impacts that are easily quantifiable in terms of profit, low prices or higher revenues, those that are less quantifiable and affect the environment, public health and the quality of life.

While the easily quantifiable economic impacts can be broadly defined and understood, those that affect welfare are ill-defined and highly subjective. There have been numerous reports and studies that have catalogued what might be considered as having impact on social welfare. Examples of these include:

The British Academy's report lists five key functions of the arts, humanities and social sciences in contributing to social welfare and quality of life, including contributions to cultural and intellectual enrichment (British Academy, 2004). This concept is further developed by recognising, as socio-economic impacts, the following: influence on cultural performance; expertise to support the historic environment; supporting the sustainability of national identity, multicultural tolerance and interaction; fostering the debate that involves conflicting moralities, traditions and beliefs; and support for civic virtues and open government.

The PA Consulting and SQW consulting report (PA Consulting/SQWconsulting, 2006), commissioned by Research Councils UK, groups impacts from funded research into four headings: development of human capital, business and commercial, policy, and quality of life. Quality of life is an especially difficult grouping to define and the report 
underlines how contributions to quality of life generate 'social benefits over and above efficiency saving'. Their description of quality of life benefits include: healthcare benefits for patients and carers; prediction of environmental impacts; social cohesion and enhanced security; and cultural advances including improvements in our understanding of the fundamental laws of nature.

Godin and Doré (2004) present a typology of categories of the impact of science on society (see table 2 below, where 'culture' refers to how individuals understand the reality around them; 'society' is concerned with behaviours and practices of individuals and groups; and 'symbolic' refers to the gains in credibility of non-academic communities from being associated with academic research):

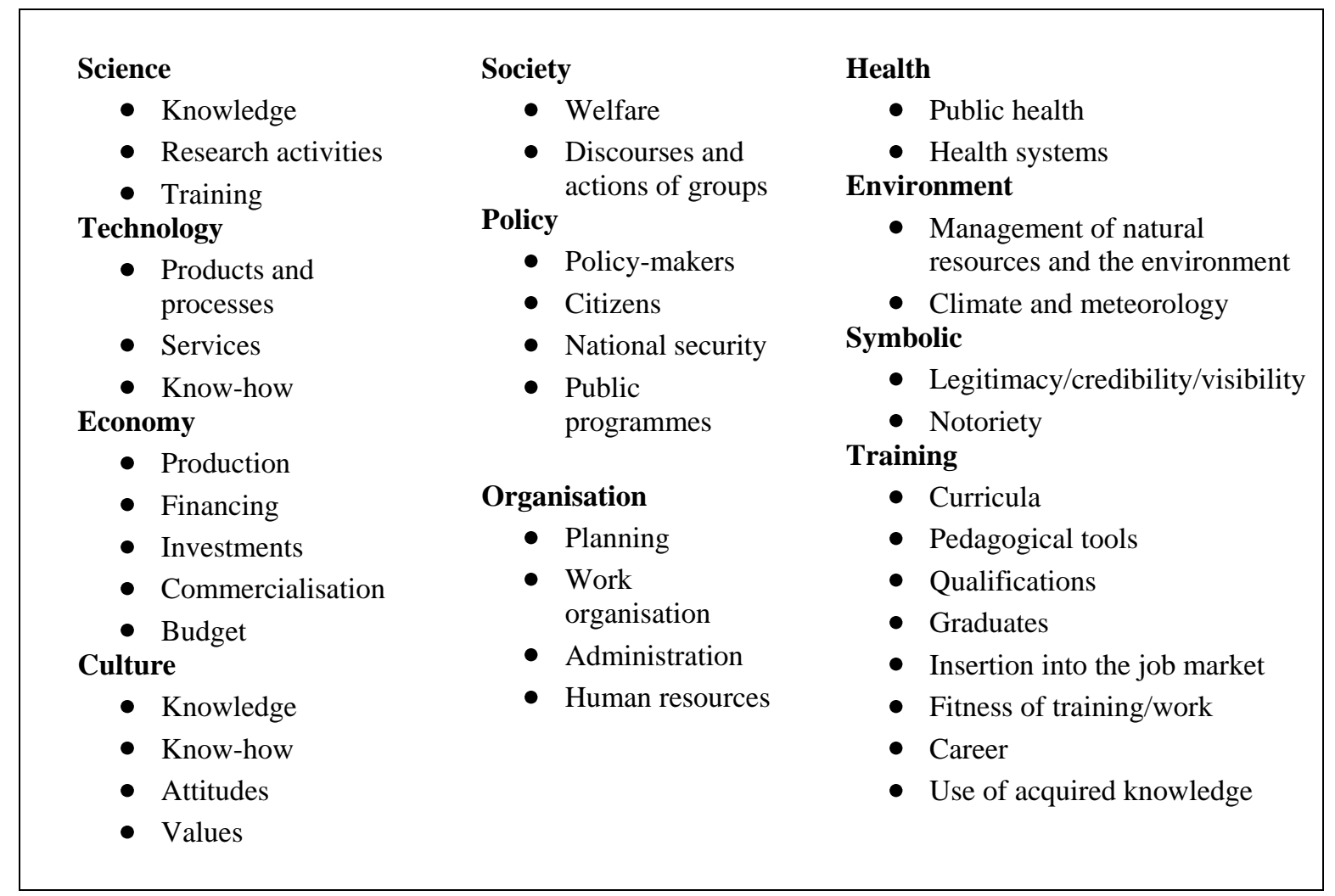

Table 2 - Godin and Doré Typology of Categories of Impact

What emerges is that the definition of socio-economic impact is very broad and diverse and covers all aspects of social welfare. Under such broad definitions the challenge for institutions is to capture all socio-economic impact of their research activities and to be able to evidence the outcomes. 


\section{Institutional strategies for the management of the socio-economic impact of research}

The challenges for institutions are multiple, but they focus around three main areas of activity:

1. How to support academics in the identification and tracking of socio-economic impact.

2. How to devise a system for academic managers to be able to systematically assess and compare the different socio-economic impacts generated by the research activity.

3. How to identify strategies that might enhance the achievement of high socioeconomic impact.

\section{Identification and tracking of socio-economic impact}

There are several models for illustrating the mechanisms or pathways from research to research outputs through to socio-economic impacts, some of which are related to specific disciplines or areas of research. The communality is that they all attempt to describe why and how impact was generated incorporating problems with time lag and attribution of impacts. The study of these pathways can provide a considerable advantage in understanding which characteristics to look for when determining the likelihood of a research activity producing socio-economic impact.

An institutional plan for the collection of socio-economic impact should, therefore, firstly be concerned with the most effective way to target research activity and research areas that have a high probability of resulting in socio-economic impact. This can be done by concentrating on a number of characteristics (for example, active user involvement at the research design stage, or dissemination of research outcomes to knowledge brokers/lobby groups/professional associations) that can be identified by understanding the generation of socio-economic impact pathways and mechanisms.

However, given that socio-economic impact must, by definition, arise in a non-academic community, the minimum requirement for any research activity is to have, on their path to impact, at least one 'contact-point' outside academia. This is schematically illustrated in figure 1 by two distinct pathways.

These can be direct (Fig. 1a) as, for example, research that is developed in close collaboration with a particular user and, therefore, by definition in constant contact with the user. However, they can also be indirect (Fig. 1b) in cases where, for example, an algorithm developed in a discipline such as applied mathematics is then employed by engineering research to solve a particular industrial problem. 


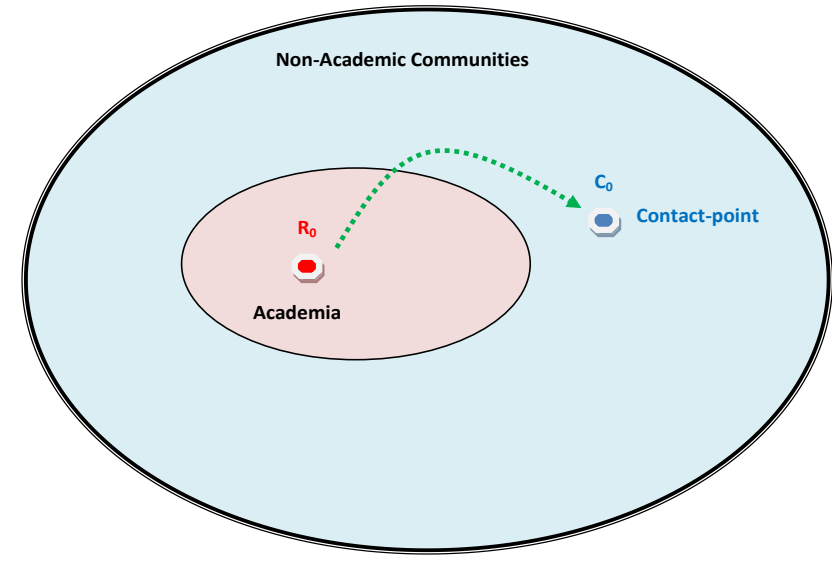

$1 \mathrm{a}$

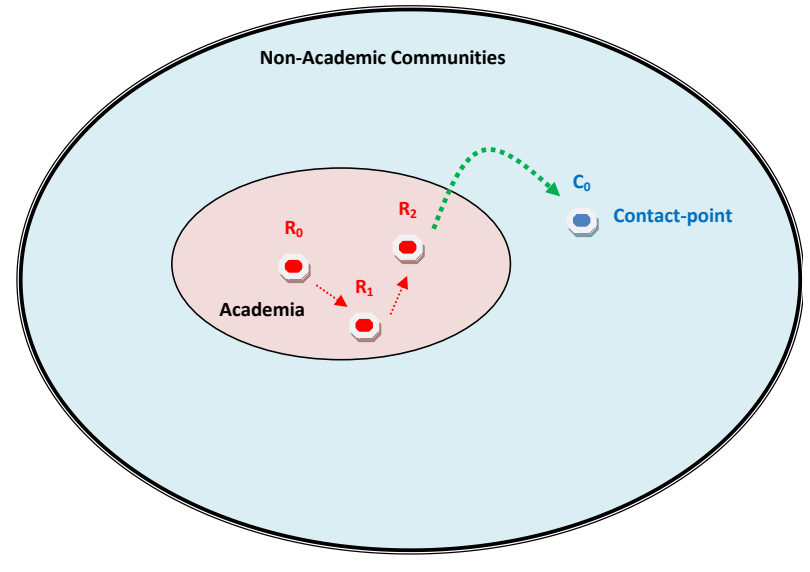

1b

Figure 1: Schematic Representation of Prerequisite to Socio-Economic Impact (R-research, C-contactpoint)

The diffusion of socio-economic impact needs to be considered also and might vary, as schematically illustrated in figure 2. Diffusion models reflect such variations while also noting timescale effects and strength of impact of an innovation (see for example the seminal works by Rogers, 1962, and Brown, 1981, and the recent major review by Greenhalgh, Robert, MacFarlane, Bate, \& Kyriakidou, 2004). Nevertheless, the engagement of users (in the broadest sense), whether proactively or by chance, is an essential prerequisite for the generation of socio-economic impact.

For example, the spread of research in a non-academic community can occur by a user spreading the research findings as 'good practice' within its user community (Fig. 2a), or, by a research activity directly engaging with a number of user's within a community (Fig. 2b).

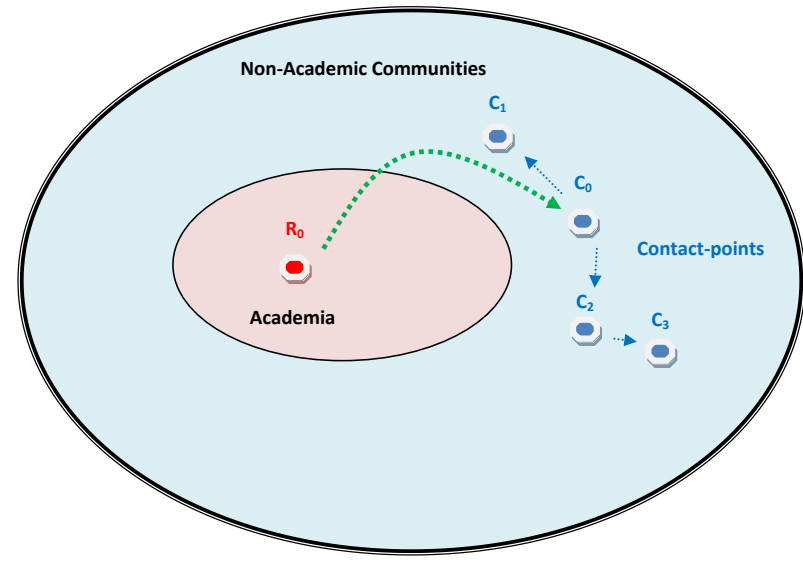

$2 \mathbf{a}$

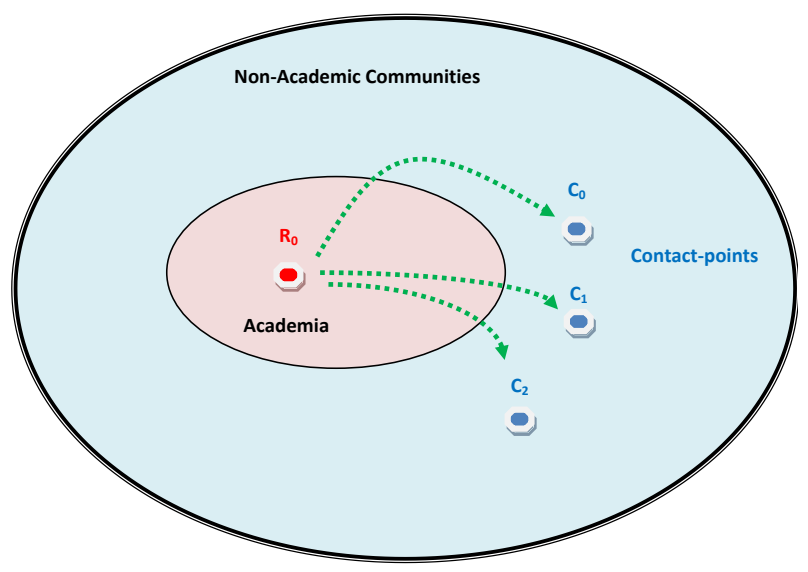

2b

Figure 2: Schematic Representation of Impact Diffusion (R-research, C-contact-point)

The first point of contact outside academia might not always be an end-user, but, an organisation or individual that can broadly be defined as a knowledge broker. As noted as long ago as 1983, knowledge brokerage roles can be structural, as through working parties or committees, or they can reside in individual roles such as those of liaison officers (Kogan and 
Henkel, 1993; Kogan, Henkel, \& Hanney, 2006). An organisation conducting a brokerage role might not directly benefit from the research activity, but can operate as a facilitator or intermediary between research activity and end-users. Examples of these organisations are learned societies, professional bodies and even the media. These groups tend to draw outcomes that might be useful for the community they represent from the academic knowledge pool.

An example of these sorts of engagements concerns the research undertaken by one of the authors on copyright infringement in the Textile Industry (Dickson \& Coles, 1998), where the research findings were disseminated in the form of non-academic reports and conference presentations not only directly to the user firms but also to professional bodies (such as Art \& Design Colleges) and lobby groups (eg, ACID - Anti-Copying in Design) that represented such firms.

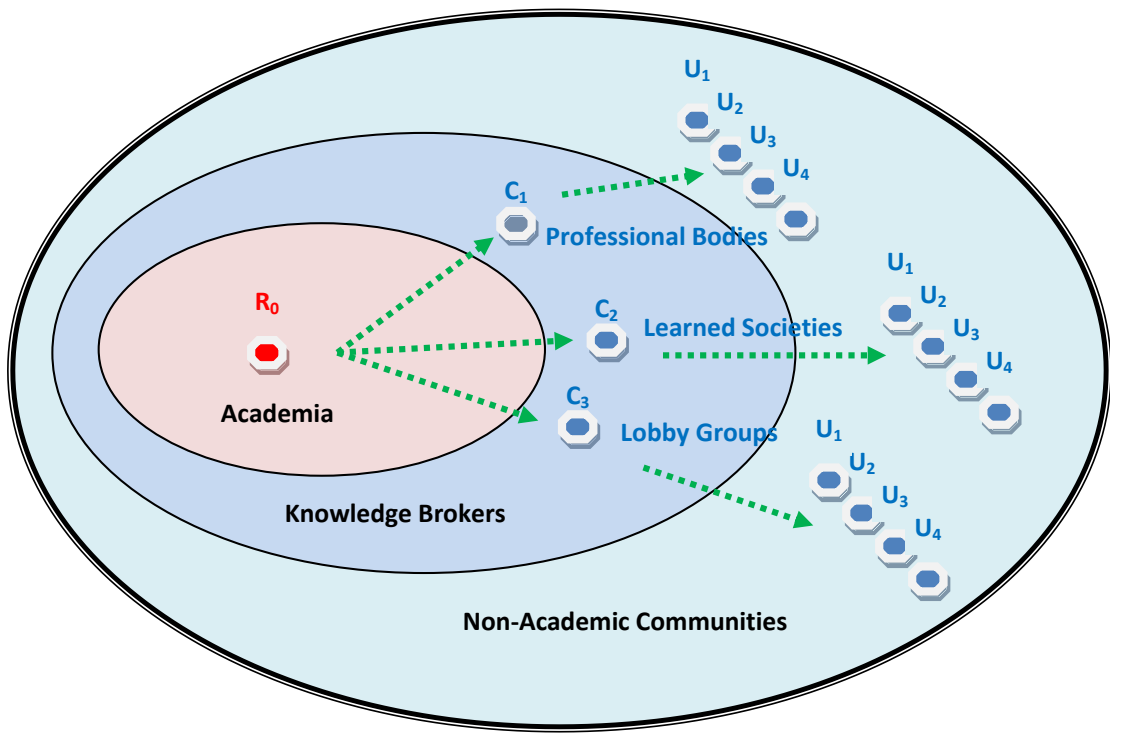

Figure 3: Schematic Representation of Knowledge Broker's Role (R-research, C-contact-point, U-user)

These representations of pathways to impact and the focus on user contact-points are powerful tools when systematically engaging with the academic community. The obstacles in trying to identify where research activity could have led to impact are greatly reduced by focusing attention on the most simple prerequisite of user engagement. This represents only the first step that indicates the dissemination of the research outcomes to non-academic environments. However, given that dissemination and engagement are not proxies for socioeconomic impact, focus must immediately be directed to verify if the engagement activity has resulted in a change as described in Godin and Doré (2004) typologies of categories of the impact.

\section{Systematic assessment and comparison of socio-economic impacts}

\section{Brunel pilot study framework}

A pilot conducted at Brunel University (Scoble, Dickson, Fisher, \& Hanney, 2009) revealed that a matrix type framework (Brunel Research Impact Device for Evaluation - BRIDE) can helpfully assist in assessing and comparing socio-economic impact. Building on an earlier use of two dimensions on which to evaluate the extent of the impact (Hanney, Davies, \& 
Buxton, 1999), the 2009 pilot showed that using depth and spread as the two primary criteria to evaluate impact originating from research activity allowed for a systematic assessment of different types of identified impacts. The depth dimension indicates how transformational, to the end-user, the application of the research findings was, while the spread signifies how large a community or communities it has affected. The figure below illustrates the matrix and shows how, having four different levels for both depth and spread, the matrix can be shaded into areas that might be assessed as having comparable socio-economic impact.

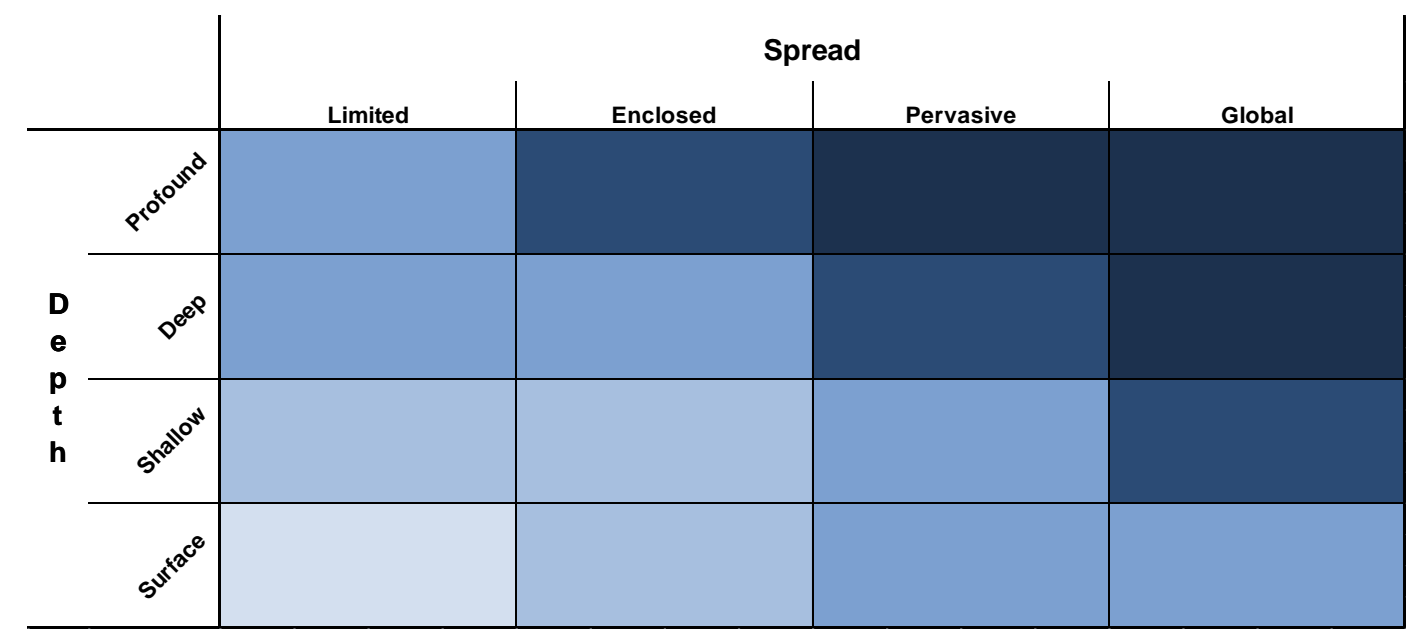

Figure 4: BRIDE Assessment Matrix

While the level of depth (or change that the research activity has generated) and the spread (or how far it has permeated the user community) are based on subjective judgements, the placement on the matrix of the different cases of impact will be consistent relatively to each other.

The use of these two dimensions has also been defined as a way of assessing socio-economic impact in the HEFCE consultation document for the forthcoming Research Excellence Framework (HEFCE, 2009, p. 21). In the consultation document HEFCE describes the assessment of socio-economic impact based on two criteria:

- "how significant or transformative the impacts have been"

- "their reach (how widely the impacts have been felt)".

Thus the terms 'depth' and 'spread', as used in the BRIDE matrix, can be easily interchanged with 'significance' and 'reach'. The use of the BRIDE assessment matrix can also be extended to include a third dimension that could capture the types and nature of the benefits and, therefore, help develop a narrative of the overall socio-economic impact.

The main objective of this type of framework is not to determine the absolute value of the socio-economic impact, but mainly to identify, relative to each other, which cases might need further investigation or where there is potential to increase their socio-economic impact. Once cases are identified through the BRIDE assessment matrix, there is scope to develop strategies to encourage and enhance the generation of impact from the research activities.

\section{Strategies for the enhancement of high socio-economic impact}

An analysis of any case study in any of BRIDE's cells will show that in order to enhance the socio-economic impact of the research activity there are two main strategies to pursue.

Movement from one cell to another is a combination or vector of two factors, as illustrated in the figure below: increase in depth/significance and/or increase in spread/reach. 


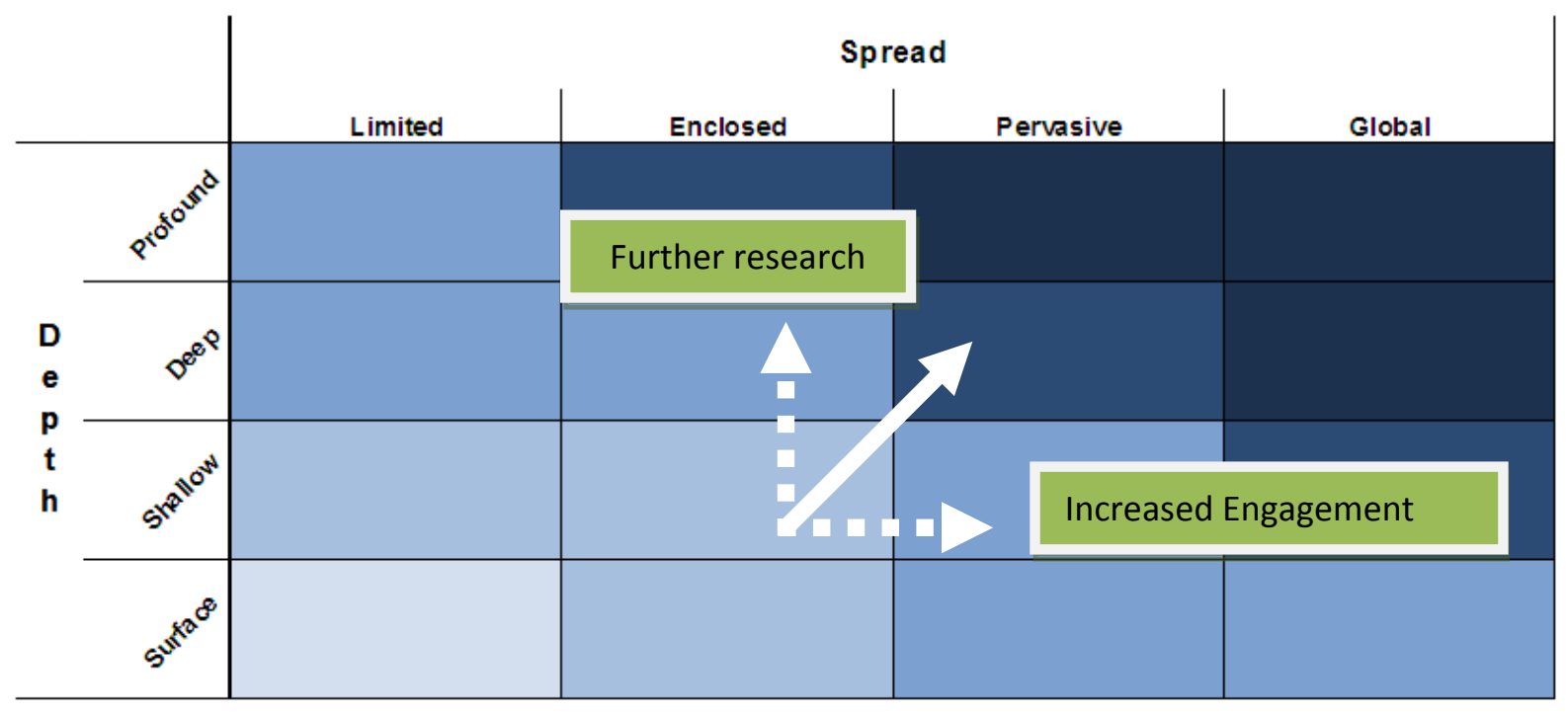

Figure 5: Strategies for the Enhancement of Socio-Economic Impact

Depth/significance is a measure of how profoundly the results and outcomes of a research activity has affected end-users and communities either through transforming businesses and industrial process, changing attitudes, improving the quality of life and other elements as illustrated in the typology of categories of impact by Godin and Doré (2004). Therefore, it can be inferred that improvement of depth/significance can be achieved by either further indepth research or by identifying end-users and communities where the outcomes of the research activity might be more beneficial.

Spread/reach is a measure of uptake of the research activity's outcomes. Any end-user or community can only be affected if they have been, either directly or indirectly, exposed to the research activity findings. It is, therefore, strategically beneficial to have a coordinating plan to maximise dissemination and active engagement of end-users and communities that might benefit from the research activity.

As a result, any strategy to improve the possibility of enhancing socio-economic impact of a research activity must be based on building the depth/significance through further quality research and developing the spread/reach through focused dissemination and engagement of non-academic communities.

A typical realistic example may help to illustrate the proposed two-pronged strategy. Consider a short pilot research project that is undertaken to identify critical factors in the survival of local small-scale theatres, funded by a regional authority. Thus it would be located in the bottom left-hand corner of the BRIDE assessment matrix, as indicated by the letter ' $A$ ' in fig 6 below, since the research is fairly superficial, being only a pilot study, and of limited spread due to its regional nature.

By doing more extensive research, with funding from say a national UK body (eg, ESRC or The Leverhulme Trust) or even from the European Union, so that wider and deeper coverage of relevant issues can be addressed, it is expected that more substantial findings and better understanding of how small theatre survive in differing socio-economic settings would be generated, leading perhaps to position ' $\mathrm{B}$ ' in the matrix. It is possible that such extended research might develop theory on the economics of drama or on entrepreneurial identity in creative industries. New theoretical insights might then lead to new national or European 
policy or support initiatives for regional theatre, thus relocating the impact position to say 'C'.

Alternatively, the pilot study might generate findings that can be reproduced as training materials for new theatre founders and managers, so the impact moves from ' $A$ ' to ' $D$ ' as the training material gets adopted by other theatres in other regions. If that proves successful in improving the survival rate of small theatres, then perhaps the training material will be approved and adopted by some major national body such as the Arts Council in the UK whose influence is widespread and may even extend beyond the UK. The effect would be to move the impact further to the right, say to ' $\mathrm{E}$ ' in the matrix in fig 6.

Of course, both pathways, from ' $A$ ' to ' $C$ ' and from ' $A$ ' to ' $E$ ', could occur simultaneously. Indeed, such complementarity is desirable and, no doubt, successful ambitious researchers would seek out any combination of opportunities to increase impact.

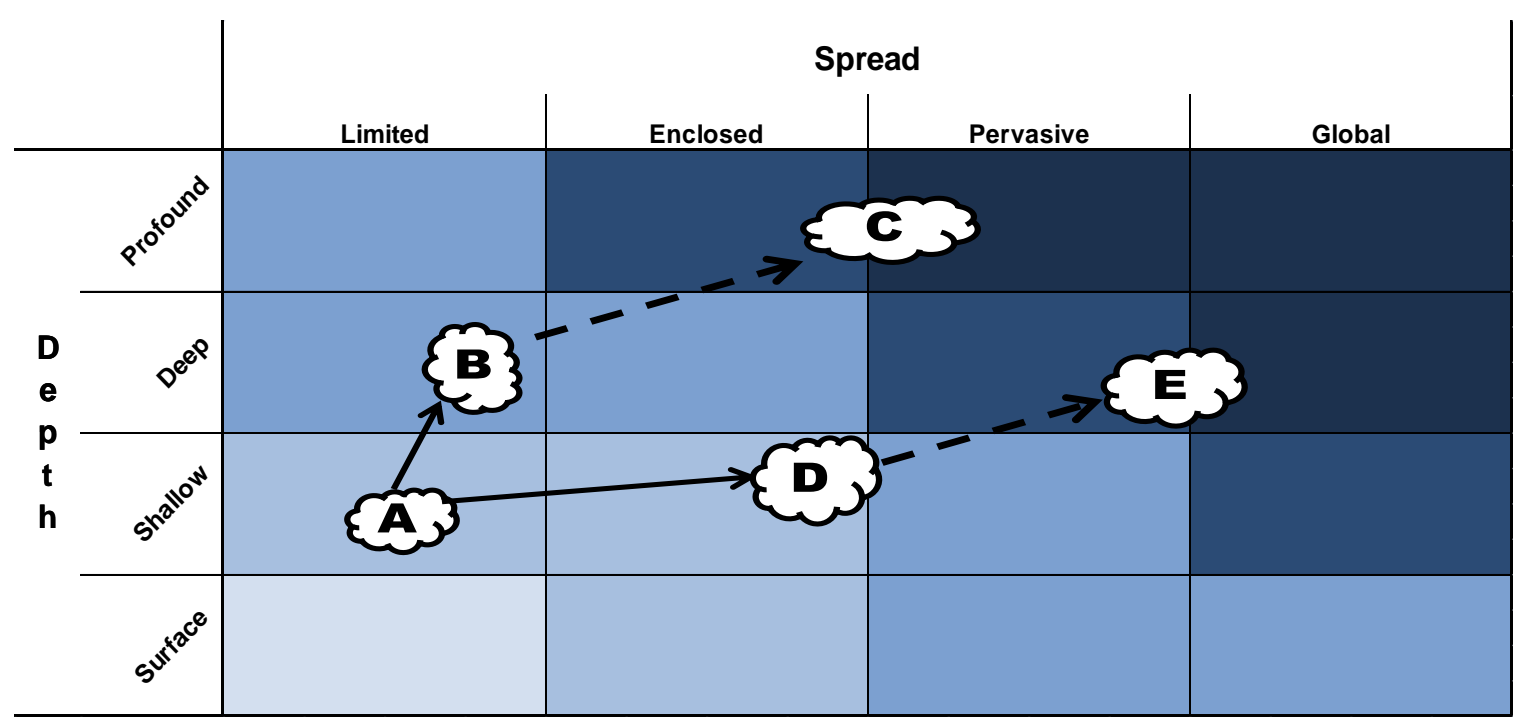

Fig. 6: Example of increasing impact of research

\section{Conclusions}

While the emerging agenda for the evaluation of socio-economic impact is challenging, coherent institutional strategies can be planned based on the understanding of the fundamental pathways from research activity to impact and by establishing frameworks based on key evaluative criteria.

The key to success in embedding socio-economic impact in the institutional research capital, given limited resources, might rely on the ability to focus researchers on the essential minimum requirements for the generation of impact and to guide them through the pathways to socio-economic impact. This approach of tracing a simplistic roadmap helps individuals identify possible occurrences of socio-economic impact that might otherwise be disguised by a lack of understanding of what needs to be sought. Once this type of approach is fully understood and implemented, tracing of socio-economic impact should become more apparent and embedded as one of the many activities for the identification of the institution's research capital.

The framework for the evaluation of socio-economic impact has to be a flexible and adaptable tool that will be most beneficial for the identification of strategies to enhance the 
possibilities of creating high-value socio-economic impact. Criteria such as depth/significance and spread/reach are essential to determine, on a basic scale, the relative value of impact. However, further categorisation of the framework to enable the evaluation by type of socio-economic impact can provide a rich picture of the overall benefits that the institutional research capital has on non-academic communities.

The expansion of institutional research capital by the inclusion of the socio-economic impact is still at an early stage. Different approaches and frameworks will be developed for capturing and evaluating socio-economic impact. In addition, these developments will be coupled with an increased understanding of disciplinary-specific pathways from research to impact and with a more engaged academic community alert to the need to follow the outcomes of the research beyond the academic domain. The growth in understanding and the development of new knowledge and new models will, inevitably, see the consolidation of systems and strategies throughout the academic sector.

\section{References}

British Academy. (2004). 'That Full Complement of Riches': the Contributions of the Arts, Humanities and Social Sciences to the Nation's Wealth.

Brown, L. A. (1981). Innovation Diffusion: A New Perspective. London: Metheun.

Buxton, M., \& Hanney, S. (1996). How can payback from health services research be assessed? Journal of Health Services Research and Policy, 1(1):35-43.

Buxton, M., Hanney, S., \& Jones, T. (2004). Estimating the economic value to societies of the impact of health research: a critical review. Bulletin of the World Health Organisation, 82:733-739.

Dickson, K., \& Coles, A-M. (1998). Design Protection and Copyright Issues for Small Textiles Firms. Design Studies, 19(2): 203-217.

DIUS. (2008). Science and Innovation Investment Framework 2004-2014: Economic Impacts of Investment in Research and Innovation.

ESRC. (2005). Approaches to Assessing the Non-Academic Impact of Social Science Research. Report of the ESRC symposium on assessing the non-academic impact of research 12th-13th May.

ESRC. (2009). Taking Stock: A Summary of ESRC's Work to Evaluate the Impact of Research on Policy \& Practice.

Griliches. Z. (1986). Productivity, R and D, and Basic Research at the Firm Level in the 1970's. The American Economic Review, 76(1):141-154.

Godin, B., \& Doré, C. (2004). Measuring the impacts of science: beyond the economic dimension. Retrieved from CSIIC Working Paper:

http://www.csiic.ca/PDF/Godin_Dore_Impacts.pdf

Grant, J., Brutsher, P.-B., Kirk, S. E., Butler, L., \& Wooding, S. (2010). Capturing Research Impacts: A review of international practice (Prepared for the Higher Education Funding Council of England). RAND Europe. RAND Corporation.

Greenhalgh, T., Robert, G., MacFarlane, F., Bate, P., \& Kyriakidou, O. (2004). Diffusion of innovations in service organisations: Systematic review and recommendations. The Milbank Quarterly, 82(4):581-629. 
Hanney, S., Davies, A., \& Buxton, M. (1999). Assessing benefits from health research projects: can we use questionnaires instead of case studies? Research Evaluation, 8(3):189199.

Health Economics Research Group, Office of Health Economics, RAND Europe. (2008). Medical Research: What's it Worth, Estimating the economic benefit from medical research in the UK. London: UK Evaluation Forum.

HEFCE. (2009). Research Excellence Framework: Second consultation on the assessment and funding of research.

HM Treasury, Department for Education and Skills, Department of Trade and Industry. (2004). Science \& innovation investment framework 2004 - 2014. HM Treasury.

Jarwal, S. D., Brion, A. M., \& King, M. L. (2009). Measuring research quality using the journal impact factor, citations and 'Ranked Journals': blunt instruments or inspired metrics? Higher Education Policy and Management, 31(4):289-300.

Kogan, M., \& Henkel, M. (1993). Government and research: the Rothschild experiment in a government department. London: Heinemann Educational.

Kogan, M., Henkel, M., \& Hanney, S. (2006). Government and research: thirty years of evolution. Dordrehct: Springer.

Mansfield, E. (1980). Basic Research and Productivity Increase in Manufacturing. The American Economic Review, 70(5): 863-873

PA Consulting/SQWconsulting. (2006). Research Councils UK: Study on the Economic Impact of the Research Councils.

RCUK. (2006). Increasing the Economic Impact of Research Councils: Advice to the Director General of Science and Innovation, DTI from the Research Council Economic Impact Group.

Rogers, E. M. (1962). Diffusion of Innovations. New York: Free Press.

Scoble, R., Dickson, K., Fisher, J., \& Hanney, S. (2009). Research impact evaluation, a wider context: Findings from a research impact pilot. Retrieved from Brunel University Research Archive: http://hdl.handle.net/2438/3475

Shelley, L. (2010). Research managers uncovered: changing roles and 'shifting arenas' in the academy. Higher Education Quarterly, 64(1):41-64.

Wooding, S., Nason, E., Starkey, T., Hanney, S., \& Grant, J. (2009). Mapping the impact: Exploring the payback of arthritis research. RAND Europe: RAND Corporation. 